ment by the medical profession in all matters affecting the conditions of its academic life. It is for the community to provide the apparatus of medicine for the doctor. It is for him to use it freely in accordance with the standards of the profession and the requirements of his oath."

1 Welch, C. E., New England fournal of Medicine, 1973, 288, 292.

2 Lancet, 1974, 1, 60.

Brook, R. H., and Appel, F. A., New England fournal of Medicine, 1973, 288, 1323.

4 Klein, R., British Medical fournal, 1973, 2, 528.

5 Klein, R., Complaints against Doctors. London, Knight, 1973.

6 Klein, R., New Society, 17 January 1974, p. 130.

7 Dollery, C. T., in Challenges for Change, ed. G. Mclachlan. London, Nuffield Provincial Hospitals Trust, Oxford University Press, 1971.

8 McIntyre, N., British Medical fournal, 1973, 2, 598.

9 Peterson, P., Fournal of the American Medical Association, 1973, 224, 884.

10 Peterson, P., Fournal of the American

10 Weed, L., unpublished observations.

12 Bevan, A., cited by Dunlop, D., in Medical Annual, 1972. Bristol, Wright, 1972 .

\section{Diagnosis of Rubella}

Acquired rubella is a trivial disease. A few swollen glands, a little suffusion of the eyes, slight catarrh perhaps, and spotsthe average attack amounts to little more; but for the spots many patients would scarcely realize they were ill. Many rubella infections are inapparent, so that clinical diagnosis is not possible; but as C. S. Peckham points out in her article on p. 259 inapparent and clinically manifest infections with rubella virus in pregnant women may differ in their liability to cause damage to fetal tissues. The clinical manifestations of the disease are therefore worth studying in some detail.

The rash, which is the most characteristic feature, consists of pale pink macules varying in size from a pinhead to 3 or $4 \mathrm{~mm}$. Their colour is more delicate than the dusky hue of the measles spot and not so fiery red as the erythema of scarlet fever. The spots appear first on the face, usually only a few in number, though occasionally both cheeks are flushed with an almost continuous rash. On the trunk there is often only a thin sprinkling of spots to begin with, but within 12 hours they are scattered all over and spilling on to the limbs. The spots usually remain discrete, especially on the limbs, but sometimes on the trunk they run together to give a general reddening of the skin, but without the puncta of scarlet fever. In an epidemic one gets accustomed to the delicate pink appearance of the rash, but in sporadic cases it can be difficult to distinguish from that of early measles or mild scarlet fever.

Enlargement of lymph nodes is a very constant finding and usually precedes the rash, perhaps for as long as a week. In the neck the suboccipital group, the postauricular mastoid group, and the chain along the posterior edge of the sternomastoid muscle are most often affected, the nodes in the anterior triangle less frequently. The enlargement is usually slight, and in a thick neck the nodes can be difficult to feel; but they can be seen like little grapes under the skin of a thin patient. They are not very tender, but patients usually are aware of their presence and often complain of a stiff neck. Tenderness of lymph nodes disappears quickly, but the enlargement may still be palpable several weeks after the illness.

The mucous membranes of the mouth are pale and clean, quite different from the congested and dusky red appearance in measles. The fauces are often a little injected and in some patients, usually adult women, there may be a few flecks of exudate on the tonsil. This exudate may lead to confusion with scarlet fever if the rubella rash is slightly atypical and especially if the woman has some mild arthralgia of the small joints of the hands: such arthralgia has been a feature in some epidemics of rubella. It is wise to take a throat swab: haemolytic streptococci will be abundant in scarlet fever, but absent or in negligible number in rubella. The conjunctivae in rubella are often suffused with faint pink, but there is none of the acute conjunctivitis seen in measles.

The diagnosis of rubella can sometimes be made with ease, especially during epidemics. Inapparent rubella can be diagnosed only by serological tests. There are several difficulties. If a pregnant woman is known to be seronegative before possible exposure a rise in titre after exposure is diagnostic. Often the original immune status is not known, and one subsequent serological test may be difficult to interpret. The time interval can be important, for IgM appears early but disappears a few weeks after infection, whereas IgG appears later but tends to persist, so that if $\operatorname{IgM}$ is detected in the serum it has probably been provoked by recent infection. ${ }^{1-6}$ Reinfection with rubella virus can occur both in women who have previously had an attack of rubella and in women immunized by vaccine. ${ }^{7-9}$ Such reinfections are usually inapparent, and they appear to provoke IgG antibodies but not IgM. Something can therefore be deduced by careful serological testing - and the interpretation can be of vital importance to the pregnant woman and the unborn child. Clinician and microbiologist must study the findings together. ${ }^{10} 11$

1 Best, J. M., Banatvala, J. E., and Watson, D., Lancet, 1969, 2, 65.

2 Lancet, 1969, 2, 90.

${ }^{3}$ Vesikaris, T., and Vaheri, A., British Medical fournal, 1968, 1, 221.

4 Cohen, S. M., Ducharme, C. P., Carpenter, C. A., and Deibel, R., Fournal of Laboratory and Clinical Medicine, 1968, 72, 760.

5 Burgin-Wolff, A., Hernandez, R., and Just, M., Lancet, 1971, 2, 1278.

- Banatvala, J. E., Best, J. M., Bertrand, J., Bowern, N. A. and Hudson, S. M., British Medical fournal, 1970, 3, 247.

7 Boué, A., Nicolas, A., and Montagnon, B., Lancet, 1971, 1, 1251.

8 Horstmann, D. M., Liebhaber, H., Le Bouvier, G. L., Rosenberg, D. A. and Halstead, S. B., New England Fournal of Medicine, 1970, 283, 771.

- Lapinleimu, K., Pyhala, R., Siimes, K., and Heigl, Z., Scandinavian Fournal of Infectious Disease, 1972, 4, 173.

10 Dudgeon, J. A., Public Health, 1972, 86, 207.

11 Dudgeon, J. A., Peckham, C. S., Marshall, W. C., Smithells, R. W., and Sheppard, S., Health Trends, 1973, 5, 75.

\section{White Marks on Nails}

White spots on the nails are usually of no significance-they may be the result of a very minor trauma. Occasionally pushing back the cuticle during manicure will result in white lines extending right across the nail in series separated by areas of normal pink nail. The appearance in these cases is always very white. The white stripes seen in chronic arsenical poisoning are usually known as Mees's stripes, ${ }^{1}$ though they had been described earlier by F. Sabin. ${ }^{2}$

In $1954 \mathrm{R}$. Terry $^{3}$ noted that the whole nail plate may become very pale in chronic liver disease, and in $1956 \mathrm{R}$. C. Muehrcke ${ }^{4}$ described narrow white bands parallel to the lunule in severe chronic hypoalbuminaemia due to chronic renal disease. Ten years later J. B. Hudson and A. J. Dennis drew attention ${ }^{5}$ to transverse white lines on the nails in both acute and chronic renal failure. The half-and-half nail ${ }^{6}$ is a condition where the proximal half of the nail is pale or white and the distal half is darker than normal. This too is seen in renal failure.

A further cause of white lines has now been reported 7 by R. T. Shanhani and E. K. Blackburn. They noted two white bands separated by bands of normal pink colour on the nails 
in a patient with Hodgkin's disease. This patient also had a white proximal part to the nail and a dark brown colour distally, similar to the half-and-half nail. Review of $\mathbf{5 0}$ patients with Hodgkin's disease brought to light three more patients with one to three white bands on the nails. In each of these four patients the nail change portended a serious prognosis, as all died within a few months of its occurrence. The changes are clearly not specific to Hodgkin's disease but when they do occur the outlook appears to be grave.

1 Mees, R. A., Nederlands Tijdschrift voor Geneeskunde, 1910, 1, 391. 2 Sabin, F., Bulletin of the fohns Hopkins Hospital, 1901, 12, 221.

3 Terry, R., Lancet, 1954, 1, 757.

4 Muehrcke, R. C., British Medical fournal, 1956, 1, 1327.

5 Hudson, J. B., and Dennis, A. J., Archives of Internal Medicine, 1966, 117, 276.

6 Lindsay, P. G., Archives of Internal Medicine, 1967, 119, 583.

7 Shahani, R. T., and Blackburn, E. K., British Fournal of Dermatology, $1973,89,457$.

\section{Internal Carotid Stenosis}

Of the extracranial arterial lesions which cause symptoms of transient cerebral ischaemia, the most common are internal carotid stenosis, vertebrobasilar insufficiency, and lesions of the first part of the subclavian artery associated with the subclavian steal phenomenon. The first reported ${ }^{1}$ successful carotid reconstruction was in 1954, and since then endarterectomy of a stenosed internal carotid artery has become a standard and successful method of treatment. At the same time the incidence of operative deaths and postoperative strokes cannot be ignored. In a recent series J. A. De Weese and colleagues ${ }^{2}$ described 103 cases with one operative death and six postoperative strokes-a $6.8 \%$ incidence of events directly attributable to surgery.

Operative hazards are acceptable only if the later progress of patients can be shown to be significantly improved by the procedure. Evidence is now becoming available on the incidence of transient cerebral ischaemia in communities and the relative merits of operative and non-operative treatment for internal carotid stenosis.

H. R. Karp and his colleagues ${ }^{3}$ found 28 patients with transient cerebral symptoms in a community of 2,455 patients over 40 years of age when those with a previous stroke and neurological damage had been excluded. As might have been expected, the incidence was higher in the white population (15.9/1,000 men and 11.5/1,000 women) than in the black population (7.9/1,000 men and 7.8/1,000 women). Temporary paralysis of a limb was the dominant symptom, and other common symptoms were altered sensation, aphasia, visual disturbance, and disturbances of equilibrium. Nineteen cases were regarded as carotid in origin and nine vertebrobasilar. This community incidence was considerably higher than the $1 \cdot 1 / 1,000$ population/year reported by $S$. D. Friedman and others ${ }^{4}$ and the $0 \cdot 3 / 1,000 /$ year reported by J. P. Whisnant and his colleagues. ${ }^{5}$

Evidence of the value of surgery in carotid lesions has been provided by the Joint Study of Extracranial Arterial Occlusion, from which several papers have been published. The results in 316 patients with transient cerebral ischaemia randomly allocated to surgical treatment (169 cases) and non-operative treatment (147 cases) were presented ${ }^{6}$ in 1970 . In the surgical group there was an $11.2 \%$ incidence of serious complications (3.5\% mortality, $7 \cdot 7 \%$ postoperative strokes) compared with a $1.4 \%$ incidence (one death and one major stroke) in the nonoperative group during investigation in hospital which included arteriography. Despite this high incidence of early disasters, the number of patients remaining symptom-free within the average follow-up period of 42 months was overwhelmingly in favour of the surgical group $(P<0.001)$. Furthermore it is probable that the mortality rate of carotid endarterectomy and the risk of postoperative stroke in major vascular centres is much lower than these figures would suggest and that the greatest risks occur in patients undergoing bilateral surgery. ${ }^{6}$

An earlier report from this survey ${ }^{7}$ had dealt with the cumulative survival rates in surgical and non-surgical groups and indicated that long-term survival in patients with transient cerebral ischaemia due to internal carotid stenosis is better following surgery than can be achieved by non-operative methods. On the other hand, if there is residual neurological damage from previous cerebral incidents non-operative treatment gives a better survival than surgical treatment.

The results of carotid surgery, as in all branches of arterial surgery, depend on the careful selection of patients. Adequate and skilled clinical assessment should precede arteriography. The chance discovery of a carotid bruit during routine clinical examination in the absence of ischaemic symptoms is not a prime indication for arteriography and must be assessed in the context of the disease pattern with which the patient has presented. The presence of a loud carotid bruit in a patient with transient cerebral ischaemia who is otherwise fit is a primary indication for arch aortography, supplemented as necessary by carotid arteriography. The existence of other symptoms and signs increases the probability of a remedial arterial lesion and transient blindness, micro-emboli in the retinal arteries, or reduced retinal artery pressure are highly specific indicators of internal carotid stenosis. ${ }^{8}$

Arteriography is undertaken with the intention of proceeding to operation, but it will not always show a marked degree of internal carotid stenosis. ${ }^{8}$ Improvement in radiological delineation of the internal carotid may be obtained by arch aortography with the head in an oblique position, or by biplane arteriography. When a remedial lesion has been demonstrated surgical treatment by an experienced operator can be confidently recommended and the results to be expected are excellent. ${ }^{6} 7$ The safety of operation may be increased by the use of intraoperative shunts carefully inserted to avoid precipitating platelet emboli, hypercapnia, anticoagulants, and E.E.G. monitoring. Operative risks can never be completely eliminated but there is no longer any doubt about the value of successful surgery.

1 Eastcott, H. H. G., Pickering, G. W., and Rob, C. G., Lancet, 1954, 2, 994.

2 De Weese, J. A., Rob, C. G., Satran, R., Marsh, D. O., Joynt, R. J., Summers, D., and Nichols, C., Annals of Surgery, 1973, 178, 258.

3 Karp, H. R., Heyman, A., Heyden, S., Bartel, A. G., Tyroler, H. A., and Hames, C. G., Fournal of the American Medical Association, 1973, 225, 125.

4 Friedman, G. D., Wilson, W. S., Mesier, J. M., Colandrea, M. A., and Nichaman, M. Z., Fournal of the American Medical Association, 1969, 210, 1428 .

5 Whisnant, J. P., Matsumoto, N., and Elveback, L. R., Neurology, 1972, 22,

- Fields, W. S., Maslenikov, V., Meyer, J. S., Hass, W. K., Remington, R. D., and MacDonald, M., fournal of the American Medical Association, R. D., and MacD

7 Bauer, R. B., Meyer, J. S., Fields, W. S., Remington, R., MacDonald, M. C., and Callen, P., fournal of the American Medical Association, 1969, $208,509$.

${ }^{8}$ Ramirex-Lassepas, M., Sandok, B. A., and Burton, R. C., Stroke, 1973, 4, 537 . 